\title{
Os blogs pró-Ana e a experiência da anorexia no sexo masculino
}

Pro-Ana blogs and the anorexia experience in males

Thamires Citadini de Almeida

Centro Universitário Metodista. Porto Alegre, RS, Brasil.

E-mail: thami_citadiniळyahoo.com.br

\section{Cristian Fabiano Guimarães}

Universidade Federal do Rio Grande do Sul. Porto Alegre, RS, Brasil. Universidade do Vale do Rio dos Sinos. Porto Alegre, RS, Brasil.

E-mail: cfguimaœuol.com.br

\section{Correspondência}

Thamires Citadini de Almeida

Rua Asteca, 16, - Protasio Alves. Porto Alegre, RS, Brasil. CEP 91260-060.

\section{Resumo}

Este artigo analisa os blogs pró-anorexia, ou blogs pró-ana, produzidos por indivíduos do sexo masculino, para entender o comportamento anoréxico masculino e o espaço que os blogs ocupam na vida desses sujeitos. Nosso objetivo foi explorar elementos relacionados com a cultura de magreza disponível nos blogs, tendo em vista analisar a questão da anorexia em homens, bem como compreender como os mesmos vivenciam essa experiência. Trata-se de pesquisa qualitativa, realizada em blogs brasileiros e estrangeiros cujos autores das páginas eram homens. Os resultados sugerem que essa população faz da internet uma rede de apoio, com características de ajuda mútua e de produção de autonomia. Por meio dos blogs, os homens discutem alternativas para ludibriar a família e socializam estratégias entre os pares para atingir o objetivo da manutenção do baixo peso. Percebemos que os profissionais da saúde devem prestar atenção para esta "rede informal" de apoio mútuo, uma vez que os blogs pró-ana têm contribuído para a promoção do comportamento anoréxico no sexo masculino.

Palavras-chave: Anorexia Nervosa; Homens; Internet; Blogs. 


\section{Abstract}

This article analyzes pro-anorexia blogs, or pro-Ana blogs, produced by men to understand the anorexic male behavior and the space that these blogs occupy in the life of these individuals. Our goal was to explore factors related to the culture of thinness that is available on the blogs, in order to analyze the issue of anorexia in men, as well as understand how they feel about this experience. This is a qualitative study conducted in Brazilian and foreign blogs authored by men. The results suggest that, to this population, the internet is a support network with characteristics of mutual aid and autonomy production. Through the blogs, men discuss alternatives to deceive their families and socialize strategies to achieve the goal of low weight maintenance. We conclude that health professionals should pay attention to this "informal network" of mutual support, as the pro-Ana blogs have been contributing to promote the anorexic behavior among men.

Keywords: Nervous Anorexia; Men; Internet; Blogs.

\section{Introdução}

$\mathrm{Na}$ atualidade, fica evidente a luta que é travada e o preconceito que existe com relação à obesidade, ao mesmo tempo em que se produz um "sobrepeso" devido ao comportamento alimentar do mundo moderno e ao modo de vida contemporâneo. Enquanto a obesidade é denunciada como um problema de saúde pública, uma vez que várias doenças crônicas estão a ela relacionadas, os meios de comunicação têm valorizado o corpo esbelto e anunciam, quase que cotidianamente, novos produtos destinados à perda de peso.

Todos esses elementos compõem um contexto no qual as pessoas se sentem obrigadas a possuir um corpo idealizado, adotado socialmente como modelo ideal do corpo perfeito, ou seja, aquele corpo magro e malhado. Sabe-se que aquela pessoa que não consegue se enquadrar dentro desse perfil, consequentemente, se sente descartada, fora de moda e, até mesmo, excluída de alguns círculos sociais. Com esse padrão estabelecido, observa-se um esforço muitas vezes exagerado para alcançar o peso ideal, pois as pessoas acreditam que assim serão mais valorizadas e admiradas. Assim, não é raro conhecermos pessoas que não estão acima do peso, porém vivem fazendo algum tipo de dieta, pois se sentem insatisfeitas com o próprio corpo. Na maioria dos casos, esses indivíduos se tornam obcecados por estar em forma, ultrapassando limites e comprometendo sua saúde.

É nesse contexto que surgem os chamados distúrbios alimentares como a anorexia nervosa, caracterizada por uma busca excessiva da magreza, associada a um medo fóbico de engordar. Tal transtorno representa uma patologia que, devido à restrição alimentar, pode causar sérias consequências à saúde do sujeito e levar à inanição. A anorexia nervosa enquanto transtorno alimentar é típica da adolescência, mas não só dela. Trata-se de uma patologia que provoca no indivíduo uma extrema preocupação com a gordura corporal, resultando em problemas psiquiátricos graves. Entre as manifestações encontradas em sujeitos portadores desse transtorno está uma importante perda de peso, decorrente da restrição alimentar autoimposta, e a distorção da imagem corporal.

Sempre que nos referimos à anorexia nervosa, imediatamente imaginamos mulheres extrema- 
mente preocupadas com o corpo, que são capazes de tudo para emagrecer. Porém o culto ao corpo não se restringe ao universo feminino. Visivelmente estão surgindo novos padrões estéticos para os homens, sendo a preocupação com o aspecto físico notável, bastando observar as ironias referentes aos "pneus" que surgem em seus quadris na convivência cotidiana com diferentes pessoas do sexo masculino, independente da idade. Por exemplo, um estudo realizado por Fernandes (2007) mostrou que crianças e jovens não estão satisfeitos com seu corpo. Este trabalho foi realizado com 1.183 alunos com idade entre 6 e 18 anos, demonstrando que $62,6 \%$ não estavam satisfeitos com a sua forma corporal, mesmo que mais de $80 \%$ dos entrevistados estivessem com peso adequado, sendo que dos insatisfeitos, $32 \%$ eram do sexo masculino.

Com esses dados, podemos constatar que cada vez mais os rapazes estão preocupados com sua aparência e, portanto, pensa-se que não hesitem em adotar uma dieta radical para perder peso, assim como as mulheres, o que contribui para o surgimento de transtornos alimentares no universo masculino e justifica a necessidade de trabalhos que entendam o comportamento anoréxico nessa população.

Há vinte anos, tínhamos uma proporção de aproximadamente 20 mulheres para cada homem com anorexia nervosa. Nos dias de hoje, esse número varia em torno de 10 mulheres para cada homem. Esse aumento dos casos pode estar relacionado com a nossa cultura, que pressiona as pessoas a terem um corpo cada vez mais magro e perfeito. Com isso, emagrecer, para alguns indivíduos, passa a ser uma meta que assume grande importância em sua vida, chegando, em casos extremos, a se tonar um transtorno alimentar, como é o caso da anorexia nervosa.

De acordo com a Organização Mundial de Saúde (OMS, 1993), a anorexia nervosa é compreendida como uma síndrome que causa uma deliberada perda de peso induzida e/ou mantida, causando alterações endócrinas e metabólicas no organismo do paciente. Porém o anoréxico não consegue perceber que sofre de uma doença, pois a patologia agride sua capacidade de juízo crítico da realidade. Inicialmente temos uma restrição alimentar, que vai se desenvolvendo gradualmente até chegar ao ponto da total recusa de alimentos. Os pacientes apresentam uma extrema insatisfação com seu próprio corpo, o que faz com que idealizem e atinjam um baixo peso corporal e o entendam como "saudável". Desse modo, a vida do sujeito que sofre com esse distúrbio alimentar se dá em torno de dietas, da comida, do peso e da imagem corporal; os pacientes apresentam um grande medo de engordar.

No que diz respeito aos estudos epidemiológicos da anorexia nervosa, encontramos algumas dificuldades, porque caracteristicamente o transtorno é egossintônico, ou seja, quem sofre do distúrbio não se reconhece como doente, fazendo com que muitos não busquem ajuda de profissionais qualificados para o tratamento, o que pode ocasionar dados de incidência e prevalência subestimados. Especificamente no sexo masculino, as taxas de prevalência ainda não foram completamente estabelecidas. Uma possível razão para esse fato seria creditada ao baixo número de casos. Essa ideia se associa à crença que se manteve por muito tempo de que a anorexia nervosa ocorria apenas em mulheres, ocasionando a exclusão dos homens nos diagnósticos. Porém observa-se, na história do transtorno, relatos de casos masculinos descritos por Richard Morton em 1689 e William Gull, em 1874. Mas o gênero masculino só passa a chamar a atenção dos pesquisadores a partir do século XX.

Contudo, entre os anos de 1955 e 1984, a anorexia nervosa apresentou um aumento anual constante de casos novos. Estima-se que a incidência média anual do transtorno na população é de 18,5 a cada 100 mil mulheres e 2,25 a cada 100 mil homens (Hay, 2002).

Atualmente, observa-se que os homens estão muito mais preocupados com a sua aparência e com o seu corpo, devido às mudanças culturais que vêm acontecendo em nossa sociedade. Nesse contexto, muitos têm colocado em risco sua própria saúde na tentativa desesperada pela perda de peso, buscando em blogs "pró-ana" dicas de como emagrecer de maneira rápida e menos sofrida. Os blogs pró-anorexia, ou pró-ana, são páginas da internet nas quais os sujeitos interagem com outras pessoas que se identificam com o tema e defendem a anorexia como um estilo de vida.

Esses blogs lidam com a anorexia nervosa a partir de uma visão positiva sobre o assunto, contribuindo para a adesão e manutenção das dietas e promovendo o comportamento anoréxico. Trata-se de diários virtuais, em que o autor fala de sua rotina, expressa 
seus pensamentos, publica vídeos e músicas sobre o tema em questão com o objetivo de dar dicas de como se tornar ou permanecer anoréxico, comportamento esse adotado pelos membros como um estilo de vida. Além disso, os usuários podem trocar informações, contar suas experiências, socializar os "deslizes" ou "recaídas" e as técnicas que utilizam para "enganar" a fome. A postagem de imagens de pessoas extremamente magras, muitas vezes, é utilizada pelo autor da página como um exemplo de modelo a ser seguido.

A falta de conhecimento dos profissionais de saúde, em casos de anorexia no sexo masculino, muitas vezes, acaba por dificultar o diagnóstico e atrasar o tratamento, podendo dessa forma aumentar o risco de complicações clínicas. Somado a isso, não encontramos na literatura estudos que focalizassem a produção da experiência anoréxica a partir da análise das redes sociais, blogs ou outras publicações na internet sobre o tema em questão. Sendo assim, o presente trabalho aborda um assunto pouco conhecido em nossa sociedade e ainda pouco discutido pelas disciplinas da saúde, especialmente quando relacionado ao comportamento dessas pessoas no espaço virtual e ao modo como a experiência da anorexia se produz nesses espaços.

Dessa forma, a situação problemática que colocamos para ser resolvida no presente trabalho busca entender qual experiência de comportamento anoréxico é forjada por homens na internet, especialmente nos blogs pró-ana. Para isso, nosso objetivo foi explorar elementos relacionados com a cultura da magreza disponíveis nos blogs na internet, tendo em vista analisar a questão da anorexia no sexo masculino. Nos blogs, buscamos identificar as características do comportamento anoréxico masculino e compreender a experiência dos homens a partir do que foi escrito pelos mesmos nessas páginas da internet.

No próximo capítulo, apresentaremos a construção histórica da anorexia, tendo em vista obter subsídios para discutir posteriormente a experiência dos homens a partir da leitura dos blogs. Em seguida, mostraremos como nosso estudo foi realizado, ou seja, o método de trabalho. Posteriormente, apresentamos os resultados do trabalho, evidenciando como a experiência da anorexia se materializa a partir das discussões produzidas nos blogs, bem como o sentido que esses espaços virtuais assumem na vida desses indivíduos.

\section{A construção histórica da anorexia e suas características}

A palavra anorexia tem origem grega anorektos (an+ orektos) que quer dizer "sem desejo, sem apetite". Porém muitos autores discordam de que no transtorno haja falta de apetite, já que para eles os anoréxicos deixam de ter apetite somente nas fases avançadas da doença e nunca no início (Busse, 2004).

Não é de hoje que a restrição alimentar está presente em nossa sociedade, ela tem uma longa caminhada antes de chegar aos dias atuais como uma patologia. Conforme Herscovici (1997), datam da Idade Média os primeiros relatos a respeito de uma doença misteriosa, que provocava modificações no corpo de quem dela padecia e que tinha como característica uma notável perda de peso, a partir de uma dieta autoimposta.

De acordo com Fernandes (2006), os primeiros relatos de jovens que recusavam a alimentação, as chamadas jovens jejuadeiras, podiam ser vistos nos séculos V e XVI. Primeiramente, esse tipo de comportamento era entendido como uma escolha divina, e no auge da Inquisição passou a ser interpretado como efeito de forças demoníacas. Entre os anos de 1200 e 1500 , era muito comum a prática de jejum pelas mulheres, sendo que, com esse tipo de comportamento, eram consideradas pessoas santas ou milagrosas, pois conseguiam sobreviver apesar do estado de extrema debilidade que ficavam após dias sem se alimentar.

0 médico Richard Morton, em 1691, registra as primeiras descrições da anorexia nervosa. Ao se deparar com uma jovem que não se alimentava, declarou que ela tinha a aparência muito magra, que seus pelos se transformaram em penugens, que estava com os batimentos cardíacos diminuídos, hipotérmica, hipotensa, além de suas extremidades apresentarem uma coloração arroxeada. O curioso, neste caso, era que tais aspectos não se justificavam por nenhuma causa orgânica. Robert William, em 1790, descreve o caso de um jovem denominado por ele como "um caso marcante de abstinência", que apresentou as mesmas características descritas por Morton (Busse, 2004).

No período do Renascimento, passamos a observar um interesse pelas "doenças da alma": "as 
perturbações do espírito começam a ganhar uma constelação científica, embora se mantenham atrelados a uma visão religiosa. As forças antinaturais que atuam no organismo são reconhecidas como emanadas do diabo" (Trillat, 1991, p. 33). Nesse sentido, "os jejuns prolongados, sendo obra do demônio, fazem das mulheres vítimas de possessão. A renúncia em comer, que foi experimentada na Idade Média como forma de devolução, passa a ser vista como ato demoníaco, herege ou insano" (Gorgati, 1999, s/p). Na mesma linha de pensamento, Weinberg e Cordás (2006) destacam que, a partir da Reforma, é observada uma diminuição da anorexia santa: "mulheres como Clara de Assis e Catarina de Siena podiam, por meio do jejum, afirmar sua própria personalidade em reação ao mundo que tentava dominá-las. Entretanto, com o advento da Reforma, a autonomia religiosa das mulheres passou a ser encarada como uma heresia ou obra do diabo, levando ao declínio do comportamento" (Weinberg; Cordás, 2006, p. 18-19).

Portanto, é possível notar que, na passagem da Idade Média para o Renascimento, houve uma mudança no modo de compreender o comportamento anoréxico das mulheres. Se na Idade Média elas eram interpretadas como santas próximas a Deus, no Renascimento passaram a ser vistas como bruxas, temidas por ter relação com o mal e o diabo. Nesse sentido, Gaspar (2010) destaca que o comportamento anoréxico no período da Idade Média, considerado como expressão divina, não gerava desassossego, já que era visto como uma prática religiosa; porém, no momento em que foi interpretado como expressão demoníaca, surgiram muitas preocupações. Diante das indagações, a Igreja solicitou as primeiras pesquisas sobre o comportamento anoréxico, com o objetivo de confirmar a veracidade e a origem dos jejuns.

Além da dimensão religiosa, é possível perceber que as jovens não se utilizavam do jejum somente com o intuito de comunicação com Deus, mas também viam nesse comportamento anoréxico um meio de protesto às imposições da cultura da época. Nesse sentido, Fernandes (2006) cita como exemplo Catarina de Siena que, aos seis anos de idade, teve uma visão de Jesus fazendo o sinal da cruz e, aos sete, ela decide abrir mão de sua sexualidade e dedica a sua virgindade para Virgem Maria. Entretanto, seus pais pretendiam casá-la com o marido da irmã que havia falecido no parto. Assustada com essa ideia, ela corta os cabelos e sua mãe a castiga encarregando-a de todos os afazeres domésticos. No período de três anos, Catarina levou uma vida de trabalho, reclusão e oração, até que o pai fica sabendo de seu voto de castidade. Ele então se convence de sua castidade e a liberta do castigo, para que assim ela pudesse viver conforme seu desejo. Ela continuou com sua devoção, se alimentando muito pouco, apenas bebendo água, pão e se alimentando de ervas cruas, intercalando com períodos de total abstinência. Por volta de 1380 , ela recusa definitivamente qualquer tipo de alimentação e, tendo seu corpo reduzido a ossos, acaba morrendo.

Ainda segundo Fernandes (2006), foi somente no século XIX que a patologia teve importantes descrições clínicas, através dos relatos de William W. Gull, em 1868, na Inglaterra, e de Ernest-Charles Lasègue, em 1873, na França. O primeiro descreve o quadro clínico de três pacientes entre 14 e 18 anos, e atribuiu ao fenômeno relatado o nome de apepsia histérica passando, em 1874, a utilizar o termo anorexia nervosa. 0 autor também relata um caso de anorexia nervosa em um paciente do sexo masculino. 0 segundo pesquisador publica um texto sobre anorexia no Archives Générales de Médecine, no qual descreve o quadro clínico da doença que permanece válido ainda na atualidade. Neste artigo, o médico francês enfatiza informações sobre o manejo do tratamento, especialmente sobre a relação do doente com o terapeuta e com a família. Portanto, foi a partir do relato desses autores que a anorexia passou a se constituir como um objeto de estudo no âmbito médico.

Sobre a existência de casos no sexo masculino ao longo da história, Sophia (2011) destaca que Robert Whytt divulgou, em 1764, o relato de um adolescente de quatorze anos que apresentava comportamento anoréxico e bulímico, o que ele chamou de "atrofia nervosa". Robert William, em 179o, também relata o caso de um rapaz que morreu após jejuar por 78 dias.

Após se constituir como objeto de estudo da medicina, a anorexia nervosa passou a ser interpretada de outras formas. Herscovici (1997) relaciona o transtorno a uma dificuldade de ter autonomia, criar 
uma identidade e aceitar a separação. Nesse sentido, Hild Bruch (1973) considera “as anoréxicas" pessoas dependentes que demonstram falta de controle sobre suas próprias funções corporais.

Já os autores Gabbard (1998) e Tavares (2007) destacam que o transtorno é mais presente nas chamadas "boas meninas", que sempre buscaram atender às expectativas dos pais, procurando agradá-los. Os autores sugerem que, dessa forma, esses indivíduos não fazem nada pelo seu próprio desejo, o que faz com que, ao chegarem ao período da adolescência, passem a expressar sentimentos de revolta como uma tentativa de encontrar um self. Essa revolta é entendida por Bruch (1987) como uma busca de autocura. Assim, o desenvolvimento da anorexia surge como "uma tentativa de autocura para desenvolver por meio da disciplina do próprio corpo um sentido de self e eficiência interpessoal. As anoréxicas transformam sua ansiedade e problemas psicológicos através da manipulação da ingestão alimentar e tamanho do corpo" (Bruch, 1987, p. 211).

De acordo com os autores apresentados, percebemos que através da abstinência alimentar, os anoréxicos conseguem ter um controle de si mesmos, transferindo as suas ansiedades e problemas psicológicos para o ato de comer e para a questão do peso. Tais reflexões nos mostram as diferentes manifestações orgânicas, emocionais, psíquicas e comportamentais presentes no transtorno, que se fazem importantes para o entendimento dinâmico da anorexia.

Atualmente, no que diz respeito ao comportamento, o discurso médico-psicológico sustenta que os anoréxicos normalmente são perfeccionistas e sensíveis a críticas; por essa razão, encontram dificuldades de lidar com as pressões sociais, uma vez que se sentem avaliados em função de seu corpo. Nesse sentido, Herscovici (1997) destaca algumas características presentes em pessoas que sofrem de transtorno alimentar, entre elas: a baixa autoestima; a dificuldade nos processos de separação-individualização; obsessividade; e compulsividade. Outro aspecto comum nos portadores desse distúrbio são os problemas relacionados à imagem corporal. Em função disso, eles não se enxergam como magros, percebendo defeitos em seu corpo ou em alguma par- te dele. Os atuais sistemas classificatórios de transtornos mentais, DSM-IV-TR e CID-10, classificam a anorexia nervosa como uma preocupação excessiva com o medo de engordar, levando os pacientes a se engajarem em dietas extremamente restritivas ou à utilização de métodos inadequados para alcançar o corpo ideal. O DSM-IV-TR (Associação Americana de Psiquiatria, 1995) ainda classifica o distúrbio em dois subtipos: o restritivo (apenas dieta e exercícios), podendo utilizar diuréticos; e o bulímico/purgativo (presença de episódios de compulsão e/ou purgação, além de dieta e exercícios).

Especificamente em relação às manifestações clínicas da anorexia no sexo masculino, Cunha (2008) destaca que no homem o transtorno aparece mais cedo do que na mulher, a perda de peso é maior em um terço dos casos e, de modo geral, os pacientes tiveram sobrepeso antes de "adquirir" a doença. Tais aspectos, evidenciados pela autora, são relevantes para nosso estudo, uma vez que os blogs encontrados são de jovens do sexo masculino que, como veremos, tinham histórico de obesidade antes de desenvolver o comportamento anoréxico.

\section{Método}

A estratégia metodológica utilizada nesse estudo foi a pesquisa de natureza qualitativa, através do estudo de caráter exploratório, e pesquisa documental utilizando blogs na internet. Blog é uma palavra de origem americana e surge da redução das palavras web e log, que significa "diário de bordo". o correto seria weblog, porém passou a ser espalhado como blog. No Brasil, a utilização desse recurso se iniciou por volta do ano 200o, embora já fosse conhecido em outros países (Schittine, 2004, p. 12). Essas páginas são destinadas a publicações que expressam ideias, pensamentos ou opiniões sobre um ou vários assuntos, sejam do autor do blog ou de outras pessoas que interagem no espaço virtual.

A pesquisa qualitativa tem como objetivo compreender "o contexto onde algum fenômeno ocorre" (Víctora; Knauth; Hassen, 200o, p. 37). Nesse sentido, a proposta inicial da pesquisa foi buscar contato com indivíduos do sexo masculino que faziam parte de comunidades virtuais. Devido à dificuldade encontrada em conversar com essas pessoas, partir- 
mos para a investigação de blogs construídos por homens que discutem o tema da anorexia nervosa, a fim de saber o que os mesmos expressam sobre essa temática. Tomamos os blogs como documentos para realizar a nossa pesquisa.

Portanto, com a finalidade de atender aos objetivos deste estudo, utilizamos como dado de pesquisa os blogs pró-ana, que são muito conhecidos pelos indivíduos que cultuam a anorexia nervosa como um "estilo de vida". Nesses blogs, os usuários buscam incentivar novos adeptos a esse comportamento por meio de dicas de como se tornar ou permanecer anoréxico. Através desses sites, muitos jovens expõem o sofrimento e o sacrifício pelo qual se submetem para alcançar um ideal de beleza criado pela sociedade. Dessa forma, essas comunidades virtuais funcionam como diários eletrônicos em que os usuários podem registrar suas tentativas de sucesso ou fracasso para manter o comportamento anoréxico. Desse modo, esses blogs constituem-se como importantes fontes de pesquisa e informações sobre a questão em análise nesta pesquisa.

Realizamos um levantamento de blogs masculinos no período de julho a outubro de 2013, no qual encontramos sete blogs com aproximadamente 166 postagens. Após a coleta das postagens publicadas nesses sites, buscamos entender a anorexia no cotidiano desses homens. Através da análise dos principais elementos discursivos das mensagens, foi possível se aproximar do modo como esses rapazes vivenciam a experiência da anorexia. Portanto, a análise dos dados se deu através da leitura de todas as mensagens postadas nos blogs, nas quais fomos destacando os principais aspectos que se repetiam a fim de criar eixos de análise que permitiram discutir as principais características da experiência dos jovens, especialmente com relação àquilo que foi publicado na internet no período estudado.

Pelo fato de o presente trabalho se tratar de uma pesquisa realizada com o uso da internet, que se caracteriza como um espaço público, onde os conteúdos são compartilhados por diversas pessoas de forma aberta, ou seja, com acesso livre, não houve necessidade de submeter o estudo à aprovação do Comitê de Ética.

\section{Os blogs pró-ana e a experiência da anorexia no sexo masculino}

Os blogs "pró-ana" são páginas na internet que funcionam como um espaço para expressar livremente os pensamentos dos indivíduos que veem na anorexia nervosa um estilo de vida. Nesse ambiente, eles se sentem à vontade para expor seus esforços, fracassos, desejos e sentimentos relacionados à constante busca do corpo idealizado. Na tentativa de incentivar a permanência dos membros no mundo "pró-ana", os autores das páginas publicam relatos e fotos de pessoas extremamente magras como um ideal a ser alcançado, que pretendem servir como incentivo para outras pessoas. Por outro lado, também são publicadas fotos de pessoas obesas, mas as mesmas são relacionadas ao desprezo, representam a rejeição, o modelo do qual devem fugir a qualquer custo, conforme podemos ver abaixo:

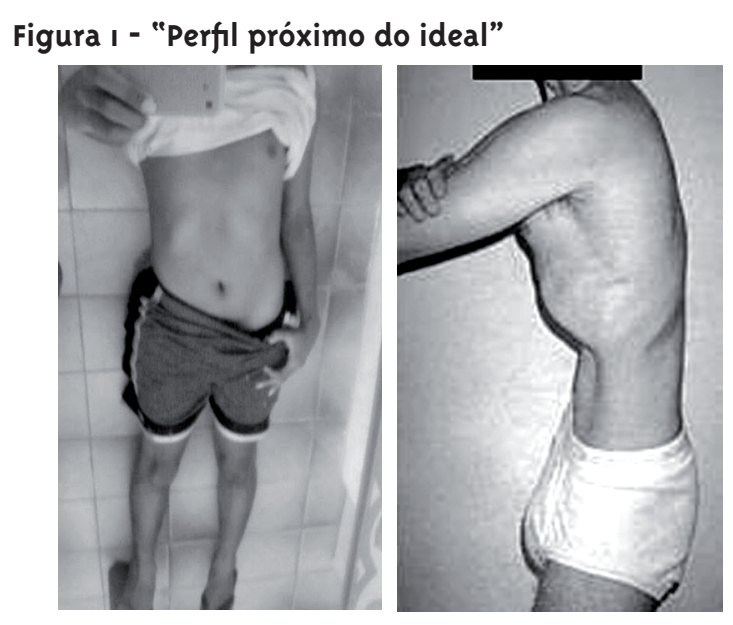

\section{Figura 2 - "Perfil a ser evitado"}

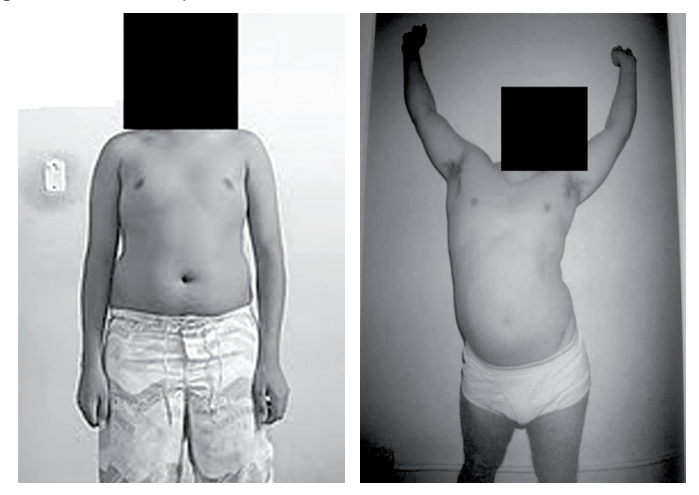

Fontes: Blog Boys 4 Perfection. Disponivel em: "http://boys 4 perfection. blogspot. com.br/?zx=b4279e4a9067f721". Acesso em: 18 jul. 2013"; e Blog Diário de um menino ana e mia. Disponivel em: "http://diariodeımeninoanaemia.blogspot. com.br/". Acesso em: 21 jul. 2013. 
Os blogs possuem ligação entre si, formando uma espécie de corrente composta por indivíduos que têm como objetivo o culto à magreza e a busca pela perda de peso a qualquer custo. Como na maioria dos casos os indivíduos que sofrem com um distúrbio alimentar acabam se isolando, essa ferramenta virtual passa a ser utilizada como veículo de socialização, com destaque para aqueles que conseguem levar ao extremo o controle do comportamento alimentar.

No que diz respeito à forma de comunicação, nota-se a utilização de um vocabulário próprio, em que "ana" representa a anorexia; "mia" significa bulimia; "pró-ana" se refere a pessoas que são a favor da anorexia; "pró-mia" são os adeptos da bulimia; "miar" significa vomitar; "NF" = No Food (em português: sem comida), ou seja, em condição de jejum, que consiste em permanecer horas ou até dias sem nenhum tipo de comida sólida, apenas ingerindo líquidos; "LF" = Low Food (em português: comidas leves), nesse tipo de jejum é permitido comer somente frutas e vegetais com moderação, finalizando o dia com a ingestão de 400 calorias. Para se ter uma ideia, um homem saudável ingere, em média, 2.000 a 2.50o calorias por dia, sendo esta a referência recomendada pelos especialistas (Candeias et al, 2005).

Alguns dos adolescentes adeptos desse "estilo de vida" portam pulseiras coloridas como uma forma de lembrete do compromisso que tem com a "ana". A pulseira vermelha mostra a anorexia; a roxa representa a bulimia; a rosa indica que a pessoa está fazendo "NF"; e a branca demonstra que o individuo está fazendo "LF". As pulseiras são utilizadas como elemento para identificação entre os pares e como fator motivador, que afirma a adesão ao comportamento restritivo próprio da anorexia nervosa, como podemos observar nos relatos abaixo:

"As pulseiras sempre me dão muita força, sempre que olho pra elas eu lembro do meu compromisso e de como quero ser; então uma dica USEM AS PULSEIRAS e quando sentirem vontade de comer olhem para elas. Hoje estou usando três (vermelha= “ana”; roxa= "mia”; rosa= "NF”)." (Postado por Dear Diary - Pró-ana/mia').
"Sempre que eu penso em cair em tentação eu olho para minhas pulseirinhas e elas me dão força para continuar. Principalmente a pulseirinha rosa que me lembra do compromisso de fazer o "no food" bem feito." (Postado por Dear Diary - Pró-ana/mia).

$\mathrm{Na}$ medida em que fomos lendo os blogs, pudemos perceber que os homens utilizam o espaço virtual como uma forma de expressar conteúdos relacionados à problemática da insatisfação com o próprio corpo. Cada página possui um modo de organização onde os visitantes podem postar comentários relacionados à temática discutida. Dessa forma, eles constroem uma espécie de rede de apoio mútuo, na qual tanto o autor do blog quanto seus visitantes podem compartilhar não só as dificuldades para chegar ao peso desejado, mas também as angústias, sofrimentos, desejos, seus medos e alegrias. Tais mensagens possuem muitas vezes caráter motivador, demonstrando compreensão e solidariedade nos momentos ruins, já que costumam ser experiências comuns aos adeptos desses grupos. Dessa forma, os blogs parecem exercer uma função de autoajuda para os indivíduos que veem na anorexia um estilo de vida, sustentando um espaço de troca de experiências e de atitudes para se manter nesse comportamento. 0 objetivo principal das postagens é dar conselhos e fazer com que os “seguidores" não desistam da busca pelo corpo perfeito. Abaixo, um comentário que mostra a função de apoio e estímulo para que a pessoa se mantenha no mundo da anorexia:

"O que é isso flor? Você foi muito bem viu! Quatro dias não é para qualquer um não! Tudo bem viu? Eu nunca consegui chegar ao quarto dia! Você é muito forte fiquei orgulhosa de você! Você fez a escolha do jantar mais leve, mais um ponto para você! Você foi muito bem, para de paranoia. Beijos e força para você continuar." (Postado por Lady, 6 de julho de 2012, às 16:02).

A preocupação com o peso é algo que costuma aparecer com bastante frequência, sendo que o ganho de quilos é visto como razão de vergonha e sinal de derrota. A gordura é entendida por esses indiví- 
duos de forma negativa e depreciativa. Ser "gordo" é interpretado como motivo de desprezo, reprovação e humilhação. Frases do tipo: "gordos são feios”; "faz mal pra quem te vê na rua"; "dá nojo"; "você é alvo de piadas" são recorrentes. Nesse sentido, observamos que a anorexia nervosa no sexo masculino se desenvolve a partir da produção do estigma/humilhação do ser gordo. Trata-se de uma intensa produção de uma imagem negativa e depreciativa da obesidade, conforme podemos observar nas mensagens abaixo:

"Bom, nem sempre fui obcecado com o meu peso, eu nunca liguei por ser um gordo, feio, nojento, sem amigos, mas certo dia, quando eu voltava da escola, começaram a me xingar de gordo, monstro, feio, depois disso, fico muito triste pensando em como minha vida seria legal, divertida e melhor se eu fosse MAGRO e não GORDO como sou. Comecei a ser pró-ana depois de procurar na internet dietas e "métodos"” para emagrecer." (Postado por Garoto Anoréxico ${ }^{2}$ ).

"Fui ao fundo do poço na minha escola. Eu acho que as ofensas foram o que me marcaram e que fizeram com que eu quisesse perder peso tão desesperadamente." (Postado por boys 4 perfection ${ }^{3}$ ).

Na maioria dos blogs analisados, a leitura atenta das postagens mostrou que esses jovens tinham histórico de sobrepeso, o que sugere que já ter sido obeso é um elemento importante para entender a gênese do comportamento anoréxico no sexo masculino. Como vimos anteriormente, Cunha (2008) também sugere esse aspecto como relevante, uma vez que as pesquisas mostram o sobrepeso e a obesidade infantil como fator de risco prevalente para o desenvolvimento da anorexia em homens, se manifestando em $50 \%$ dos casos. Além disso, observamos também que as brincadeiras de outros jovens, em relação à aparência física desses indivíduos com histórico de obesidade, desencadeiam uma tentativa desesperada de mudança, que culmina na adesão a estratégias extremas de controle de peso.

Os sujeitos passam a ter comportamentos carac- terísticos da síndrome, tais como comportamento de evitação de comida, compulsões seguidas de vômito autoinduzido, exagero nos exercícios físicos, desmaios, tontura, fraqueza, perda de peso, entre outros. Sempre desejando perder mais peso, tal comportamento é visto como sinal de perfeição pelos rapazes e valorizado socialmente pelos seus pares.

Estabelece-se um circuito de valorização, que é estimulado pelos blogs e que reforça o comportamento anoréxico, uma vez que essas pessoas experimentam sensações diferentes daquelas a que comumente elas estavam expostas quando obesas: do ridículo de ser gordo à supervalorização obtida à luz da cultura da magreza, com consequente valorização social. Os blogs funcionam dando visibilidade aos esforços envidados pelos indivíduos em direção à perda de peso. Além disso, contribuem para a reprodução de uma cultura informal sobre a anorexia, validando um conhecimento prático da vida cotidiana que é facilmente absorvido pelas pessoas que se identificam com o estilo de vida anoréxico.

Outro aspecto que ganha destaque nos blogs são as alternativas para despistar a família das estratégias utilizadas para o emagrecimento. Os anoréxicos usam várias técnicas para convencer os pais de que estão se alimentando. Muitas vezes, os indivíduos que sofrem com esse distúrbio alimentar entendem a família e, principalmente a mãe, como um “obstáculo”, já que os familiares, preocupados com sua saúde, insistem para que eles se alimentem. Nos relatos, podemos observar como esses sujeitos fazem para despistar a família:

"Tenho mentido muito, só sujo o prato e digo que comi, e fico com pacotes de salgadinho e biscoito no quarto para que pensem que estou comendo essas coisas (aproveito que sou eu quem joga o lixo fora e abro os pacotes e jogo a comida no lixo, porque se eu "como" tem que diminuir né).” (Postado por Dear Diary).

"Hoje eu comi uns pãezinhos de queijo, fui fraco. A comida joguei fora." (Postado por Diário de um menino Ana e Mia4).

\footnotetext{
${ }^{2}$ GAROTO ANORÉXICO. Disponível em: http://garotoanorexico.blogspot.com.br/search?updated-min=2011-01-o1Too:0o:0o-o8:oo\&updatedmax=2012-01-01Too:00:00-08:0o\&max-results=2.Acesso em: 10 jul. 2013.

${ }^{3}$ BOYS 4 PERFECTION. Disponível em: http://boys4perfection.blogspot.com.br/?zx=b4279e4a9o67f721. Acesso em: 11 jul. 2013. 4 DIÁRIO DE UM MENINO ANA E MIA. Disponível em: http://diariodeımeninoanaemia.blogspot.com.br/. Acesso em: 13 jul. 2013.
} 
Em relação aos jejuns praticados pelos jovens, é possível observar sentimentos que vão do entusiasmo à depressão. Quando se está conseguindo manter o controle, evitando alimentos, passando dias sem comer - quase sempre, somente à base de chá - eles se sentem bem e com a sensação de dever cumprido, o que os motiva a continuar na busca da perfeição. Tais momentos são postados nos blogs e adquirem um sentido de conquista/vitória:

"Gente eu estou muito feliz, pois consegui perder 3 kg nos dois últimos dias, não vou desistir NF (Noo Food) todo dia." (Postado por Diário de um menino ana e mia).

"Eu consegui me controlar meus anjos e resisti a muitas coisas gostosas, muitas coisas que com toda certeza me fariam engordar e estou postando me sentido leve, magro e lindo. Isso é o mais importante, estou me sentindo muito bem." (Postado por Dear Diary - Pró Ana-Mia).

"Estou muito feliz, porque conclui meu segundo dia de NF, não comi nada, somente ingeri água e chá bem gelados.” (Postado por Dear Diary - Pró Ana-Mia).

Já sentimentos intensos de desqualificação são experimentados quando o sujeito se rende à tentação do alimento, passando a se sentir muito culpado por aquilo que entende como "compulsão", como se o simples fato de se alimentar constituísse um exagero, uma perda de limites. Nesses momentos, o que se observa é o desprezo por si mesmo, uma vez que passa a se considerar fraco por se afastar da "ana".

"Pois é gente estou me sentindo péssimo, simplesmente o mais gordo do universo, a pessoa mais cheia de banha, um porco gordo cheio de pelanca, ridículo e acima de tudo um idiota que se rende às compulsões e simplesmente destrói um sacrifício de dias por um momento comendo algo que só me faz engordar e me sentir muito mal depois." (Postado por Dear Diary - Pró Ana-Mia).

Embora o nosso estudo tome como objeto de discussão a anorexia nervosa, percebe-se que, assim como na bulimia nervosa, nesta patologia existe um comportamento compensatório. Cunha (2008) confirma tal hipótese, sugerindo que os anoréxicos podem intercalar episódios longos de restrição alimentar com fases de perda de controle, cedendo à rigidez do modelo alimentar autoimposto. Dessa forma, muitos anoréxicos se utilizam de métodos purgativos, como uma tentativa de perda de peso.

Como foi possível observar nos blogs, a necessidade de controle é muito presente no transtorno, e não nos parece producente que os profissionais da saúde invistam na ideia de controle alimentar como estratégia terapêutica. Afirmamos essa ideia porque entendemos que o jovem controla o que ingere numa luta por autonomia, buscando decidir algo por si mesmo, para que não seja do outro a decisão do que deve ou não comer. Para Bruch (1987), esse comportamento é esperado nas pessoas com anorexia, pois através da disciplina do próprio corpo o sujeito busca encontrar um sentido que lhe devolva o senso de existir de forma autônoma e independente. Visto dessa forma, o comportamento anoréxico pode ser entendido como um sintoma: é pelo exercício da autonomia do que pode ou não ingerir que o adolescente explicita que existe como um sujeito diferenciado. De modo que o não se alimentar pode ser entendido como busca desesperada de reconhecimento de si mesmo, de sua autonomia.

Nesse sentido o trabalho dos profissionais com as pessoas com comportamento anoréxico, antes de se focar na aprendizagem do controle do comportamento alimentar, deveria buscar outras possibilidades de exercício da autonomia, fortalecendo-a em outras dimensões da vida do sujeito.

\section{Reflexões finais}

Ao longo da elaboração do artigo, nos deparamos com a dificuldade de encontrar estudos relacionados à anorexia nervosa no sexo masculino. Mesmo com todo o avanço do conhecimento na área dos transtornos alimentares, o baixo número de estudos relacionados à população masculina é evidente.

Ao explorarmos os blogs pró-ana de homens, encontramos elementos que evidenciam e reforçam a cultura da magreza. Assim, há uma forte tendência da sociedade em cultuar o corpo magro como um padrão de beleza ideal, valorizando a aparência das pessoas em detrimento de outros valores, tais 
como o de uma saúde em equilíbrio. Desse modo, a supervalorização da imagem corporal faz vítimas também no universo masculino: os homens se tornam a cada dia mais vaidosos e, consequentemente, com obsessões por um corpo perfeito.

Nosso objetivo nesse estudo não foi o de focar a anorexia como doença, julgando se o comportamento desses indivíduos é "saudável” ou "não saudável”. Buscamos, ao contrário, identificar elementos que pudessem falar sobre o comportamento anoréxico de homens, a partir da análise de blogs pró-ana. Nesse sentido, este estudo buscou evidenciar que tipo de discurso sobre a anorexia é produzido nos blogs pelos rapazes que escrevem suas experiências nesses espaços virtuais.

Do ponto de vista da diferença entre comportamento anoréxico no sexo masculino e no feminino, nossa análise permitiu destacar que, de acordo com os relatos existentes nos blogs, o sobrepeso ou a obesidade infantil aparecem como elementos importantes para pensar o comportamento anoréxico masculino. Essa característica pode ser importante para diferenciar a anorexia nervosa nos homens da anorexia nervosa nas mulheres. Embora esse estudo não possa concluir nesse sentido, sugerimos que outras pesquisas sejam feitas sobre este aspecto, com a finalidade de aprofundar tal constatação que já tem sido corroborada pela literatura científica.

Por outro lado, a construção do modelo pró-ana evidenciado nos blogs, entendido por algumas pessoas como um distúrbio mental e por outras como um estilo de vida, pode ser vista como expressão do sofrimento daqueles sujeitos que não se enquadram nos padrões estéticos ideais que são estabelecidos pela sociedade. Assim, esses indivíduos encontram na internet um espaço possível de identificação e cooperação com outras pessoas que, supostamente, vivem os mesmos dilemas.

Os diálogos coletados nos blogs mostraram que embora se pressuponha que os rapazes tenham dificuldades em expressar seus sentimentos, em relação à insatisfação com a aparência corporal a situação se mostra diferente no mundo virtual. A utilização desse recurso funciona como um espaço de livre expressão de tais sentimentos. Apesar da menor frequência, se comparado ao material disponibilizado na internet por mulheres sobre o mesmo assunto, os homens também possuem blogs "pró-ana" e utilizam esses espaços para descrever seus problemas pessoais, emoções e conflitos, relacionados à insatisfação com a imagem corporal, e para socializar estratégias de adesão/manutenção de dietas. Os blogs "pró-ana" são vistos por esses indivíduos como um espaço para compartilhar suas experiências com outros sujeitos que enfrentam o mesmo dilema. Dessa forma se constitui uma rede de apoio informal em que um incentiva o outro a se manter no comportamento anoréxico.

Pudemos perceber também que os blogs aparecem como forma de reação aos discursos hegemônicos da anorexia, sejam eles o discurso médico que associa o comportamento anoréxico à doença, ou aquele produzido pelos meios de comunicação de massa, que tendem a hipervalorizar a cultura da magreza. No caso dos blogs, além do contraponto a tais discursos, o que se observa são as lutas cotidianas dos rapazes para sustentar um modo de ser/existir anoréxico, sendo que fica evidente a função desses blogs no sentido de positivar esse estilo de vida.

Portanto, podemos pensar que tanto o discurso "patologizante" da anorexia produzido pelas ciências da saúde de modo geral, quanto aquele do culto ao corpo magro da cultura de massa contemporânea, são positivados nesses blogs e transformados em recursos práticos para os rapazes se inventarem no comportamento anoréxico cotidiano. Os blogs não são depositários apenas de dicas/receitas para manter o comportamento anoréxico; eles deixam clara a reivindicação do sujeito de se enunciar como anoréxico e, ao se oferecer ao olhar do outro como aquele que porta uma dica sobre o comportamento anoréxico que lhe será útil, esse indivíduo acredita estar em pleno exercício da autonomia.

Conforme discutimos ao longo deste artigo, do ponto de vista da psicanálise, a questão da autonomia é fundamental na dinâmica da anorexia, porque o sujeito vivencia uma intensa dependência e controle de sua vida no ambiente familiar. Os blogs são um recurso de exercício da autonomia para esses sujeitos, pois neles o discurso da anorexia ganha validade social e os sujeitos anoréxicos se reconhecem como importantes para a vida de outras pessoas. Sob esta perspectiva, é preciso reforçar, os blogs estão em sintonia com um sintoma da anorexia, embora constituam-se como um espaço rico que colabora para compreendermos a experiência concreta desses indivíduos. 
Os profissionais da psicologia e da nutrição, por sua vez, devem prestar atenção para esta "rede informal" de apoio mútuo, uma vez que esse espaço tem ajudado na promoção do comportamento anoréxico no sexo masculino, talvez pela possibilidade de não revelar a identidade ou pelo fato de reforçar a autonomia desses indivíduos. Sugerimos que o comportamento "virtual" da pessoa seja objeto de discussão na prática clínica, tendo em vista qualificar o olhar sobre o sujeito. As estratégias terapêuticas devem considerar o comportamento virtual dos rapazes, de modo a potencializar o efeito das intervenções clínicas. Embora neste trabalho tenhamos nos limitado aos blogs, pensamos que analisar as infinitas relações que são construídas pelos rapazes no mundo virtual, tais como em redes sociais ou canais de discussão virtuais pró-ana, pode ser importante para compreender o comportamento destes sujeitos.

Os homens procuram nos blogs um lugar onde podem se expressar sem o medo do julgamento, uma vez que nesses grupos recebem apoio, compreensão e encorajamento. Isso nos mostra que tais blogs podem ser uma ferramenta fundamental para entender como a anorexia nervosa aparece no sexo masculino. Por fim, destacamos a necessidade do desenvolvimento de outros estudos que venham contribuir com reflexões acerca da anorexia no universo masculino, pois tal patologia se constitui como um problema ainda muito pouco reconhecido em todas as suas dimensões, ao mesmo tempo que se mostra carente de estratégias terapêuticas eficazes para o tratamento.

\section{Referências}

\section{ASSOCIAÇÃO AMERICANA DE PSIQUIATRIA.}

Manual diagnóstico e estatístico de transtornos mentais: DSM-IV. 4. ed. Porto Alegre: Artes Médicas, 1995.

BRUCH, H. Eating disorders: obesity, anorexia nervosa and the person within. New York: Basic Books, 1973.

BRUCH, H. The changing picture of an illness: anorexia nervosa, in attachment and the therapeutic process. In: SACKSTEDER, J. L. et al. (Ed.). Attachment and the therapeutic process. Madison: International Universities Press, 1987. p. 205-222.
BUSSE, S. R. (Org.). Anorexia, bulimia e obesidade. Barueri: Manole, 2004.

CANDEIAS, V. et al. Princípios para uma alimentação saudável. Lisboa: Direção Geral da Saúde, 2005.

CUNHA, L. N. Anorexia, bulimia e compulsão alimentar. São Paulo: Atheneu, 2008.

FERNANDES, M. H. Transtornos alimentares: anorexia e bulimia. São Paulo: Casa do Psicólogo, 2006.

FERNANDES, A. E. R. Avaliação da imagem corporal, hábitos de vida e alimentares em crianças e adolescentes de escolas públicas e particulares de belo horizonte. 2007. Dissertação (Mestrado em Saúde da Criança e do Adolescente) - Faculdade de Medicina da Universidade Federal de Minas Gerais, Belo Horizonte, 2007. Disponível em: <http://www.bibliotecadigital.ufmg.br/dspace/ handle/1843/ECJS-76KMH6>. Acesso em: 10 maio 2013.

GABBARD, G. O. Psiquiatria psicodinâmica: baseada no DSM - IV. Porto Alegre: ArtMed, 1998.

GASPAR, F. L. Anorexia e violência psíquica. Curitiba: Juruá, 2010.

GORGATI, S. B. Corpos desencarnados: um histórico da anorexia. Psychiatry On-line Brasil, São Paulo, v. 4, n. 6, 1999. Disponível em: <http:// www.polbr.med.br/ano99/anrx699.php>. Acesso em: 13 set. 2013 .

HAY, P. J. Epidemiologia dos transtornos alimentares: estado atual e desenvolvimentos futuros. Revista Brasileira de Psiquiatria, v. 24, p. 13-17, 2002. Suplemento III. Disponível em: <http:// www.scielo.br/pdf/rbp/v24s3/13965.pdf >. Acesso em: 24 ago. 2013.

HERSCOVICI, C. R. A escravidão das dietas: um guia para reconhecer e enfrentar os transtornos alimentares. Porto Alegre: Artes Médicas, 1997. OMS - ORGANIZAÇÃO MUNDIAL DA SAÚDE. Classificação dos transtornos mentais e de comportamentos da CDI-1o: descrições clínicas e diretrizes diagnósticas. Porto Alegre: Artes Médicas, 1993. 
SCHITTINE, D. Blog: comunicação e escrita íntima na internet. Rio de Janeiro: Civilização Brasileira, 2004 .

SOPHIA, B. V. Quando a magreza torna-se um ideal masculino: um estudo socioantropológico sobre a anorexia e a bulimia em homens. 2011. Dissertação (Mestrado em Ciências Sociais) Instituto de Filosofia e Ciências Humanas da Universidade do Estado do Rio de Janeiro, Rio de Janeiro, 2011.
TAVARES, M. C. G. C. F. (org.). O dinamismo da imagem corporal. São Paulo: Phorte, 2007.

TRILLAT, E. História da histeria. São Paulo: Escuta,1991.

VÍCTORA, C. G.; KNAUTH, D. R.; HASSEN, M. N. A. Pesquisa qualitativa em saúde: uma introdução ao tema. Porto Alegre: Tomo Editorial, 2000.

WEINBERG, C.; CORDÁS, T. A. Do altar as passarelas: da anorexia santa à anorexia nervosa. São Paulo: Annablume, 2006.

\section{Contribuição dos autores}

Almeida foi responsável pela concepção e revisão do artigo. Guimarães orientou o trabalho.

Recebido: 05/02/2014

Aprovado: 16/06/2014 